
\title{
28 Research Square \\ Spatiotemporal variations of asthma admission rates and its relationship with environmental factors in Guangxi, China
}

\section{Rui Ma}

Henan University

Lizhong Liang ( $\square$ heartmaster@163.com )

The Affiliated Hospital of Guangdong Medical University

Yunfeng Kong ( $\nabla$ yfkong@henu.edu.cn )

Henan University https://orcid.org/0000-0002-0777-3116

\section{Mingyang Chen}

The affiliated Hospital of Guangdong Medical University

\section{Shiyan Zhai}

Nanyang Normal University

\section{Hongquan Song}

Henan University

\section{Yane Hou}

Henan University

Guangli Zhang

Henan University

\section{Research article}

Keywords: asthma, regional heterogeneity, environmental factors, synergistic effects, generalized additive models

Posted Date: December 10th, 2019

DOl: https://doi.org/10.21203/rs.2.18564/v1

License: (c) (i) This work is licensed under a Creative Commons Attribution 4.0 International License. Read Full License 


\section{Abstract}

\section{Background}

The association between environmental factors and asthma has attracted much attention. Numerous studies have focused on the effects of air pollution or meteorological factors, but the synergistic effects and regional heterogeneity remain unclear.

\section{Methods}

Between 2014 and 2015, 8,563 hospital admissions in 2014 and 7,804 hospital admissions in 2015 due to asthma were collected from 14 regions in Guangxi, China. First, we performed a Spearman correlation coefficient model as the single factor analysis to estimate correlation between environmental factors and asthma hospitalization rates in multiple regions. Second, Generalized Additive Model (GAM) was used to analyze the synergistic effects of environmental factors on asthma hospitalization rates in 14 regions, respectively.

\section{Results}

The results indicated that asthma hospitalization rates were high in spring and autumn. There were all nonlinear relationships between air pollutants, meteorological factors and asthma hospitalization rates, and the relationships were different from region to region. According to the single factor analysis, asthma hospitalizations were related to the daily temperature, daily range of temperature, $\mathrm{CO}, \mathrm{NO}_{2}$, and $\mathrm{PM}_{2.5}$ in multiple regions. According to the result of synergistic effects analysis, the adjusted R-square was high in Beihai and Nanning, with values of 0.292 and 0.207 , which meant that environmental factors were powerful in explaining changes of asthma hospitalization rates in Beihai and Nanning.

\section{Conclusion}

Daily range of temperature is an important factor impact on asthma, which should be considered in the analysis of environmental factors impact on asthma. It is suggested that the relationship between asthma and risk factors in different regions deserves additional study. Governments should develop targeted protective measures for asthma in different regions.

\section{Background}

Asthma is a common chronic respiratory inflammatory disease. Among susceptible individuals, asthma can cause wheeze, dyspnea, chest tightness and cough, especially at night or early in the morning [1]. Asthma is a chronic disease that seriously threatens public health. In 2004, approximately 300 million people suffered from asthma worldwide [2,3] and about 30 million people suffered from asthma in China in 2008; a figure that has been steadily increasing $[4,5]$. The risk factors for asthma include genetics, gender and the environment, while environmental risk factors include meteorological conditions, allergens in the air, viral respiratory infections, smoke, air pollution, occupation, and diet [6-8]. 
Air pollutants and meteorological factors related to asthma was reported worldwide [9-14], but the synergistic effects have not been well studied. Some studies found that climatic differences had a significant influence on asthma [9,15-19], but air pollution was not taken into account. Temperature is an important factor impact on asthma, which is measured in numerous studies [11,20-23]. Some other studies showed evidence of an association between air pollutants and asthma without considering meteorological factors [20-22,24]. Evidence was found that short-term exposure to air pollution was associated with increasing risk of hospital utilization for asthma, and children tended to be more susceptible to the effect of air pollution on asthma morbidity [25]. Some research have been done on the associations between air pollutant and meteorological factors and asthma, but the conclusions are inconsistent $[10,11,13,14,26]$.

The results were inconsistent about the relationship between asthma and environmental factors, and spatial differences in asthma should take into account $[23,25]$. The prevalence of asthma may vary with race and location [27] and changes in environmental factors in different seasons greatly influence the incidence of respiratory diseases [28]. For instance, the correlation between asthma and $\mathrm{O}_{3}$ varies with seasons, and there are regional differences in $\mathrm{SO}_{2}$ levels [29]. The associations between air pollutant concentrations and asthma hospitalization differed from region to region [30], and most studies only assessed the effects of environmental factors on asthma hospitalization in single region. Chang considered the influence of geographical factors on asthma and analyzed the relationship between food, dog ownership, housing area and disposable income from the perspective of community variables and found that asthma incidence differed by region [31], but the effects of meteorological factors and air pollution on asthma were not considered. There are significant regional changes in some environmental factors that affect asthma, but these are often ignored. It is necessary to explore the relationship between environmental factors of asthma hospitalization in multiple regions. In addition, there were lots of studies exploring association between air pollution and asthma in China. However, to our knowledge, regions of studies were often concentrated on areas with high level of air pollution in the north and central China, such as Beijing, Shanghai, Jinan, Hefei, etc $[9,11,20,18,32]$. Considering geographical differences and air pollution characteristics, it is essential to explore the impacts of air pollution on asthma in areas with low level of air pollution in southern China.

Guangxi is located in southern China with low level of air pollution. The prevalence of asthma has been reported to be at a moderate level in Guangxi, China [32,33]. In this study, we divided Guangxi into 14 regions according to the city boundary, which included both coastal and inland areas with different geographical and climatic characteristics. This study attempted to explore the spatiotemporal patterns of asthma hospitalizations and its relationship with environmental factors in 14 regions in Guangxi. First, we conducted some analysis on temporal and spatial variations of asthma hospitalization rates in 14 regions. Second, we performed single factor analysis between meteorological factors, air pollutants and asthma hospitalization rates in 14 regions. Third, we explored the synergistic effects of meteorological factors and air pollutants on hospitalization rates of asthma in 14 regions, respectively. The conclusions may provide a reference for public health departments to provide preventive measures. 


\section{Methods}

\section{Research location and data source}

This study was performed in 14 regions in Guangxi (Figure 1), China, which belongs to the subtropical monsoon climate zone [34], with terrain inclines from northwest to southeast, and has a basin shape. Vast differences in the topography of different regions exist in Guangxi, with an area of $237,600 \mathrm{~km}^{2}$. The main source of air pollution is local emissions rather than external transport [35]. Guangxi has four seasons: spring (March-May), summer (June-August), autumn (September-November), and winter (December-February).

Daily hospitalization cases for asthma were extracted from home page of inpatient medical record in general hospitals at or above the county level in Guangxi from Guangdong Medical University. The asthma data was from 1 January 2014 to 31 December 2015. Asthma data were collected from hospital records based on the disease codes defined by the 10th revision of the International Classification of Diseases (ICD-10). The content of records were diagnostic information, admission date, duration of hospital stay, age, sex, and address. There were 8563 hospital admissions in 2014 and 7804 hospital admissions in 2015 due to asthma collected by diagnostic coding of 'J45.xxx', such as 'J45.900', 'J45.901', and 'J45.902'. In addition, asthma patients were divided into 14 regions based on their addresses.

Daily data of environmental factors were collected, including air pollution concentration, and daily meteorological data from 1 January 2015 to 31 December 2015. Data on daily air pollutants were aggregated data for the 14 regions, directly collected from China air quality online Monitoring and Analysis platform, including average daily level of Sulfur dioxide $\left(\mathrm{SO}_{2}\right)$, nitrogen dioxide $\left(\mathrm{NO}_{2}\right)$, particulate matter ( $\mathrm{PM}_{2.5}$ ), and carbon monoxide (CO). Daily meteorological factors were obtained from 600 monitoring stations in the National Meteorological Information Center, including daily average temperature $(T)$, daily maximum temperature, daily minimum temperature, average relative humidity percentage (RHU), and average wind speed (WIN). Daily meteorological factors for the 14 regions were interpolated from data based on 600 monitoring sites in China. Moreover, this study introduced daily range of temperature (TDIFF) as an influencing factor, which refers to the difference between the maximum and minimum temperatures on the same day. Demographic characteristics for 14 regions were obtained from 2015 Guangxi Statistical Yearbook [36] and the Sixth National Census in 2010 [37]. The population of 14 regions in 2015 in Guangxi were available from Guangxi Statistical Yearbook, but the populations about age groups for 14 regions in Guangxi were modeled weights by an offset on the righthand side of the equation based on the Sixth National Census in 2010.

\section{Analysis model}

This study used the Spearman correlation coefficient model to complete a single factor analysis of correlation between asthma hospitalization rates and environmental factors in 14 regions. This model is 
a nonparametric index to measure the dependence of two variables, which uses a monotone equation to evaluate the correlation between them. The formula of correlation coefficient $\rho$ was:

[Due to technical limitations, equation 1 available only in the manuscript file below.]

This study also explored the synergistic effects of meteorological factors and air pollutants on asthma, using GAM based on a Poisson distribution function. GAM is a popular model to explore nonlinear relationship. In 1986, Hastie and Robert proposed the GAM, which was an extension of the generalized linear model, adopting the nonparametric form of the predictive variable and differing from the parametric form of the linear model [38,39]. The relationship between explanatory variables and dependent variables is established by using smoothing function, which is linear or nonlinear [40].the value of $\rho$ is between -1 and 1 . The response variable $y$ represented asthma hospitalization rate, and variables of $x$ were $T, T D I F F, R H U, W I N, P_{2.5}, \mathrm{SO}_{2}, \mathrm{CO}, \mathrm{NO}_{2}$. T was daily average temperature; TDIFF was daily range of temperature; $R H U$ was average relative humidity percentage; WIN was average wind speed. We used this model to assess the correlation between asthma hospitalization rates and environmental factors one by one. In this study, the values of $\rho$ represented the associations between asthma hospitalization rate and environmental factors. Positive value represents positive correlation between two variables and negative value means negative correlation, and larger values have stronger correlation. In this study, we used two-sided test, and $p$ values smaller than 0.05 were considered statistically significant. Spearman correlation coefficient model was performed in IBM SPSS Statistics (Version 21).

This study used the generalized additive model based on a Poisson distribution function and adopted the thin plate spline function as smoothing function. To eliminate interference from long-term trends and weeks on the results of the analysis, we introduced week variables and date sequence variables. This study used GCV as the estimation method, which had a wider range of uses.

[Due to technical limitations, equation 2 available only in the manuscript file below.]

We used GAM to estimate the synergistic effects of air pollutants and meteorological factors on asthma hospitalization rates. We explored the synergistic effects on different regions, considering that asthma might be affected by geographical characteristics. The effect estimates for specific age groups were pooled rather than used as individual patients. For the analysis of different age groups, we firstly counted the number of daily hospital admissions for asthma in each age group. Then, we performed GAM to analyze the association between environmental factors and the number of asthma hospitalizations for different age groups one by one. The GAM model was invoked once per age group. It's worth noting that we estimate the synergistic effects of air pollutants and meteorological factors on asthma admission number for each age group rather than admission rate. GAM was completely done in $\mathrm{R}$ (version 3.5.2) with packages of "mgcv".

In this study, Spearman correlation coefficient model was used to study the correlation of single factor between T, Tdiff, $\mathrm{RHU}, \mathrm{WIN}, \mathrm{SO}_{2}, \mathrm{NO}_{2}, \mathrm{PM}_{2.5}$, and $\mathrm{CO}$ levels and hospital admission rates due to asthma 
for 14 regions in Guangxi. Then, Generalized Additive Model (GAM) was used to explore the synergistic effects of meteorological factors and air pollutants on asthma.

\section{Results}

\section{General descriptive statistics}

According to the statistics, the ratio of males and females admitted for asthma was $52.08 \%$ and $47.92 \%$ respectively. The patients were grouped by age, with $25.88 \%$ of patients 0 to 14 years old, $4.72 \%$ of patients 15 to 29 years old, $11.57 \%$ of patients 30 to 44 years old, $22.45 \%$ of patients 45 to 59 years old, $23.37 \%$ of patients $60-75$ years old, and $12.01 \%$ of patients over 75 years old.

The seasonal descriptive statistics for asthma hospital admissions and environmental factors in 2015 were presented in Table 1. The number of admissions for asthma was high in spring and autumn, with a daily average admission number of 25.5 in spring, which was higher than other seasons. The temperature, relative humidity and daily range of temperature in winter was lower than in other seasons. The $\mathrm{PM}_{2.5}$ concentration in winter was 59.4, which was significantly higher than in other seasons and exceeded the national average primary annual concentration standard of 35 . Furthermore, the concentration of $\mathrm{CO}$ and $\mathrm{NO}_{2}$ in winter was also higher than in other seasons. The national secondary standard average annual concentration of $\mathrm{SO}_{2}$ and $\mathrm{NO}_{2}$ was 60 and 40 , respectively [41], and the indicators for the whole year and the four seasons did not exceed the standard values. In total, the overall air quality in winter was significantly worse than in the other three seasons.

The number of asthma hospital admissions varied across different months (Figure 2a). The number of asthma hospital admissions was high in January, March, April, May, June and October. Trends in hospital stay for asthma were different among age groups (Figure $2 b$ ). The number of asthma hospitalizations was highest in the 0-14 year old age group, with 44-74 years old the next most commonly admitted. The number of asthma admissions was relatively low in other age groups. This showed that younger and older patients were more likely to be admitted with asthma.

\section{Temporal and spatial distribution of hospitalization rate of asthma}

This study analyzed the spatial distribution of the daily average hospitalization rate (per 100,000 population) of asthma for 14 regions in Guangxi (Figure 3). The hospital admission rate was higher in 2014 than in 2015. The admission rate in Baise was high with the daily average admission rate in 2014 and 2015 between 30 and 35 . Fangchenggang and Liuzhou had an average daily hospital admission rate of more than 30 in 2014, but this fell to 25-30 in 2015. The average daily hospitalization rate in Hechi and Nanning in 2014 was between 25 and 30, but decreased in 2015. Daily average admission rates in other regions were relatively low. In spring, the hospital admission rate was highest in the regions of Baise, Hechi, Liuzhou, Guilin, Nanning, Hezhou, Fangchenggang, Qinzhou, and Yulin (Figure 3). In Nanning, Baise, Fangchenggang, and Wuzhou, the hospitalization rate was higher in autumn than in summer or 
winter. In Liuzhou, Guilin, Hezhou, Chongzuo, the hospital admission rate was relatively high compared to other regions.

When adjusted for regions, the time trends of ashtma hospitalization rates for different regions in 2015 were present in Figure 4. The peak of asthma hospitalization rate appeared in March-May and September-November, with a trough in February, July, and August (Figure 4). Baise, Liuzhou, Nanning, and Wuzhou had two peaks in a year (in spring and autumn). Asthma admission rates peaked in Guilin in spring and winter. The hospital admission rate in Baise, Hechi, Liuzhou and Fangchenggang was relatively high compared to other regions. The admission rates in Qinzhou, Yulin and Beihai were low and their trends were similar.

\section{Air pollutants and meteorological factors impact on asthma}

Single factor analysis

According to the result of Spearman, the correlation between air pollutants, meteorological factors and asthma admission rates in 14 regions in Guangxi was showed in Figure 5. According to Figure 5, not all correlations were statistically significant. T, Tdiff, $\mathrm{CO}$, and $\mathrm{NO}_{2}$ were correlated with asthma admission rates in multiple regions. T was positively correlated with asthma in Baise, Laibin, and Yulin, and T was negatively correlated with asthma in Liuzhou, Nanning, Qinzhou, and Beihai. Asthma was positively correlated with Tdiff in some regions. $\mathrm{CO}$ and $\mathrm{NO}_{2}$ were positively correlated with asthma in multiple regions, and negatively correlated with asthma in a few regions. Relationship between $\mathrm{CO}$ and asthma was more pronounced in central Guangxi. $\mathrm{NO}_{2}$ was related to asthma admission rate in regions of eastern Guangxi. $\mathrm{PM}_{2.5}$ had strong positive correlation with asthma hospitalization in Hechi, Qinzhou, and Beihai. $\mathrm{SO}_{2}$ was positively correlated with asthma admission rate only in Beihai and average wind speed was only found to correlate with the asthma admission rate in Yulin. There did not appear to be any correlation between the asthma admission rate and environmental factors in Chongzuo or Hezhou.

Synergistic effects analysis

We used GAM to explore the fitting effect between multiple environmental factors and the asthma hospitalization rates in Guangxi (Table 2), and the results were all statistically significant. In 2015, the fitting effect of multiple factors on asthma hospitalization rate was well in Beihai, Naning, Laibin, and Liuzhou, with adjusted R-square values of $0.292,0.207,0.190$, and 0.184 , respectively, which meant that environmental factors were more powerful in explaining changes in asthma hospitalization rates in Beihai, Naning, Laibin, and Liuzhou. The values of deviance explained were high in Beihai, Nanning, and Liuzhou, with values of $40.5 \%, 34.3 \%$, and $31.8 \%$. The synergistic effect of environmental factors on asthma was low in Chongzuo and Hezhou. The fitting effects between meteorological factors, air pollutant concentration and asthma hospitalization rate were shown in Figure 6. There were nonlinear relationships between all risk factors and asthma hospitalization rate, and the relationships were different from region to region. Although the overall relationship between environmental factors and 
hospitalization rate was nonlinear, some factors showed a linear relationship in certain intervals. When $\mathrm{PM}_{2.5}$ concentration was high, $\mathrm{PM}_{2.5}$ concentration was associated with increased risks of $\mathrm{PM}_{2.5}$ concentration in Guilin, Liuzhou, Guigang, Yulin, Hezhou, and Laibin (Figure 6). When $\mathrm{NO}_{2}$ concentration exceeded 70, the hospitalization rate of asthma was positively correlated with $\mathrm{NO}_{2}$ in Nanning, Guilin, Liuzhou and Guigang (Figure 6).

When adjusted for age, the fitting effects between multiple environmental factors and the asthma admission rate were shown in Table 3. The $0-14$ year old age group was the most sensitive to environmental factors, with adjust R-square of 0.328 . The fitting effect between multiple environmental factors and asthma was relatively low in the 15-29, 30-44, and 45-59 age groups, with R-square values of $0.122,0.148$, and 0.136 . The fitting effect on the $60-74$ age group was slightly better than that for the $15-$ $29,30-44,45-59$ and above 75 age groups. Patients aged 0-14 with asthma may be more susceptible to environmental factors than others.

\section{Discussion}

This study showed that there were significant seasonal and regional differences for asthma admission rate in 14 regions. The number of hospital admissions for asthma was high in spring and autumn. The dominant environmental factors impact on asthma hospitalizations were also different in the 14 regions in Guangxi. Among the meteorological factors, the correlation with temperature and daily range of temperature on asthma was higher than other meteorological factors. In this study, we introduced daily range of temperature as an influencing factor, which proved to be an important factor impact on asthma. In multiple regions, daily range of temperature was positively correlated with asthma hospitalization rates. Among the air pollution factors, $\mathrm{CO}, \mathrm{NO}_{2}$ and $\mathrm{PM}_{2.5}$ had the greatest impact on asthma admissions. We found that residents between 0-14 years are particularly susceptible to air pollutants and meteorological factors, which was consistent with previous study [42,43].

There were seasonal characteristics for asthma hospitalization rates. In Guangxi, there were often two peaks of hospital admissions in one year, with the peak hospitalization rate occurring in spring (MarchMay) and autumn (September-November), and the hospitalization rate was highest in spring. In other domestic and foreign studies, asthma usually occurred at high levels in spring and autumn, similar to what observed in Guangxi. Dust mites and allergens are important factors in the induction of respiratory diseases such as asthma [44,45]. More pollen and a suitable temperature for dust mites might be the cause of high incidence of asthma in spring. In addition, Baise, Liuzhou, Nanning, Wuzhou and other regions also had hospital admission rate peaks in autumn. Studies have shown that both elevated and decreased temperatures had an impact on asthma, with low temperature having a greater impact on respiratory diseases $[21,22]$, which was similar with our results in multiple regions. The temperature in Guangxi dropped in September and the air quality in autumn and winter was worse, which might explain the high admission rate of asthma in autumn and winter. Based on the generalized additive model with the Poisson link function, it was found that the sensitivity of people between 0-14 years of age and over 60 years old to environmental factors was weaker than that of 15-59 year olds. The 0-14 year old age 
group was the most sensitive to environmental factors, which might due to the incomplete development of physiological structures and imperfect immune system in patients under 14 years of age [16]. The sensitivity of patients over 60 years old to environmental factors was also relatively high, which has also been shown in other studies, and this may be attributed to a decline of physiological function and the deterioration of physique [16,17].

The asthma hospitalization rates for the regions in Guangxi were quite different and the dominant environmental factors that affected asthma admissions were not consistent. The results showed that the correlation between environmental factors and the asthma hospitalization rates was significantly different within different regions. The difference may due to the diversity of asthma risk factors, such as dust mites, plants, food, pollen, temperature changes, air pollution and smoking $[6-8,46]$ and different landforms and climatic conditions. A study of 26,455 cities in the UK found that an increase in green space was beneficial for asthma, but that pollen production might be detrimental to asthma [47]. The main features of the topography in Guangxi are that there are many mountains and less flat land and the terrain is inclined from the northwest to the southeast [35]. The hospital admission rate of asthma in the northwest and west of Guangxi was higher than that in the east or south. The hospitalization rate in northwest Guangxi was high, especially in spring, which might be due to more mountains, more plants and more pollen. The reasons for the high hospital admission rate in Baise may be more plants and a larger daily range of temperature. Fangchenggang, Beihai, Yulin and Qinzhou are all coastal regions in the south. The asthma admission rate in Beihai, Yulin and Qinzhou was low and the trend for the asthma admission rate was similar. However, the hospitalization rate in Fangchenggang was higher than the other three cities, which might be related to the higher elevation of Fangchenggang and its mountainous terrain with more plants.

Combining the results of single factor and synergistic effects analysis, there were all nonlinear relationship between environmental factors and asthma hospitalization rates. Among the meteorological factors, temperature and daily range of temperature were highly correlated with asthma, and the daily range of temperature was positively correlated with asthma in some regions. Among the air pollution factors, $\mathrm{PM}_{2.5}, \mathrm{NO}_{2}$ and $\mathrm{CO}$ were positively correlated with asthma in multiple regions. To our knowledge, there was no consensus among various studies on the air pollutants that affect the onset of asthma $[11,15,18,48-50]$. Although the relationship between asthma and exposure to $\mathrm{PM}_{2.5}$ has been frequently measured, reported conclusions have not been consistent [42]. Numerous studies found positive associations between $\mathrm{PM}_{2.5}$ and asthma $[9,20,42]$, and some studies found no obvious relationship, which was similar with our results. We found a positive correlation between $\mathrm{PM}_{2.5}$ and asthma in multiple regions, while no significant correlation was found in other regions. Some studies suggested that temperature was positively associated with asthma [20,42], but some have reported negative associations [51]. In our study, temperature was positively associated with asthma in Baise, Laibin, and Yulin, and negatively associated with asthma in Liuzhou, Nanning, Qinzhou, and Beihai. There were no significant correlation in other regions. Research on the relationship between asthma and temperature showed that both high and low temperatures had an impact on the onset of asthma [20-23,52], with low 
temperatures having a greater impact on respiratory diseases such as asthma [20,21], but Xu found that high temperatures had a greater effect on childhood asthma than cold temperatures [22]. Lam et al. suggested that the incidence of asthma increased when the maximum temperature was between $27^{\circ} \mathrm{C}$ $30^{\circ} \mathrm{C}$ [21]. Since there is no consensus on the relationship between temperature and asthma, temperature may be divided into multiple intervals for further study. Veremchuk et al. suggested that the greatest correlates of asthma were airborne particulate matter, $\mathrm{CO}$, and $\mathrm{NO}_{2}$ [10]. Zhai found that $\mathrm{NO}_{2}$ and $\mathrm{CO}$ had the greatest impact on asthma in Beijing [11,15], and Zhou et al. also found that $\mathrm{SO}_{2}$ had impact on asthma in Jinan [15]. A study found that an increase in the number of patients due to exacerbation of asthma was associated with a decrease in ambient temperature and with an increase in $\mathrm{NO}_{2}$ levels. Hospitalizations also increased with decreases in temperature, and with higher levels of atmospheric pressure and $\mathrm{NO}_{2}$. It did not find an association with $\mathrm{SO}_{2}, \mathrm{CO}$ or relative humidity levels [51]. Possible reasons for this finding were that specific meteorological conditions modified effect on the association between $\mathrm{CO}, \mathrm{O}_{3}, \mathrm{NO}_{2}, \mathrm{SO}_{2}, \mathrm{PM}_{2.5}$ and asthma hospitalizations [12,13]. In addition, weather interacts with air pollution when the relationship between air pollution and asthma is considered $[10,11,13,14,26]$. The interaction between meteorological factors and air pollution on asthma deserves further study. Uniform policy interventions may not work due to regional difference in environmental factors for diseases [49], and it is essential to formulate differentiated prevention policies for different regions.

Limitations of this study should be acknowledged. First, the 14 regions in our study are all in Guangxi province in China, which are geographically adjacent. Spatial autocorrelation may exist in the environmental data and asthma hospitalization rates in 14 regions [50]. Second, we did not consider the effect of pollen on asthma due to the lack of pollen data. Pollen may be an important factor impact on asthma, especially in spring. Third, this study did not take into account the effects of indoor pollution, and economic factors on asthma. Finally, we performed the analyses in city level, and there were still regional differences within each region. The associations between environmental factors and asthma hospitalization rates may change depending on the size of aggregated geographical units. In this study, the size of geographical units was a little large, which might mask local spatial variations for smaller geographical unit. The next step could be to refine the research area to the county level for more concrete analysis.

\section{Conclusions}

In Guangxi, the number of hospital admissions for asthma was high in spring and autumn. Residents between 0-14 years are particularly susceptible to air pollutants and meteorological factors. The asthma hospitalization rate varied in different regions and the dominant environmental factors affecting asthma were different. Among meteorological factors, temperature and daily range of temperature were highly correlated with asthma. Daily range of temperature was positively correlated with asthma hospitalization rate in multiple regions, which might be an important factor impact on asthma. Among the air pollutants, $\mathrm{CO}, \mathrm{NO}_{2}$, and $\mathrm{PM}_{2.5}$ had the greatest effect on asthma. It is essential to study the characteristics of 
asthma and take targeted preventive measures in different areas. These findings have also enhanced our understanding of the spatial heterogeneity of asthma.

\section{Abbreviations}

GAM: Generalized Additive Model

T: daily average temperature

TDIFF: daily range of temperature

RHU: average relative humidity percentage

WIN: average wind speed

PRS: average air pressure

$\mathrm{SO}_{2}$ : sulfur dioxide

$\mathrm{NO}_{2}$ : nitrogen dioxide

$\mathrm{PM}_{2.5}$ : particulate matter

co: carbon monoxide

\section{Declarations}

\section{Ethics approval and consent to participate}

This study was reviewed and approved by the Ethics Committee of Henan Medical School. We obtained daily data of hospitalization records in Guangxi, not referring to individual data. The dataset analyzed in this study is available for authors upon reasonable request and with permission of the Major Application Project of Guangdong Science Department.

\section{Consent for publication}

Not applicable.

\section{Availability of data and materials}


The daily data for air pollution is available on https://www.aqistudy.cn/historydata. The daily data for meteorology is retrieved from National Meteorological Information Center on http://data.cma.cn/. The demographic data mainly came from Guangxi Statistical Yearbook (http://www.gxtj.gov.cn/). The Sixth National Census came from CNKI (http://data.cnki.net/). The asthma-related data used in the present study is partially public, which is available from the corresponding author on reasonable request.

\section{Competing interests}

The authors declare that they have no competing interests.

\section{Funding}

This paper was supported by the Major Application Project of Guangdong Science and Technology Department (2015B010131016).

\section{Authors' contributions}

Yunfeng Kong and Rui Ma determined the core idea of the research and edited the article; Rui Ma Wrote the article; Lizhong Liang offerd the disease data and funding; Shiyan Zhai, Hongquan Song and Guangli Zhang edited the article; Yane Hou processed the data.

\section{References}

1. Immunol JA. Expert panel report 3 (epr-3): guidelines for the diagnosis and management of asthmasummary report 2007. Journal of Allergy \& Clinical Immunology. 2007; 120: 94-138. doi:10.1016/j.jaci.2007.09.043.

2. Masoli M, Fabian D, Holt S, Beasley R. The global burden of asthma: executive summary of the gina dissemination committee report. Allergy. 2004; 59: 469-478. doi: 10.1111/j.1398-9995.2004.00526.x.

3. Teresa T, Sanja S, Ginette M, Gershon AS, Bateman ED, Cruz AA, et al. Global asthma prevalence in adults: findings from the cross-sectional world health survey. Bmc Public Health. 2012; 12: 204-204. doi: https://doi.org/10.1186/1471-2458-12-204.

4. Bateman ED, Hurd SS, Barnes PJ, Bousquet J, Drazen JM, Fitzgerald M, et al. Global strategy for asthma management and prevention: GINA executive summary. Fundamentals of numerical reservoir simulation /. Elsevier Scientific Pub. Co.: distributors for the U.S. and Canada, Elsevier North-Holland. 2008; 2008: 143-178. doi: 10.1183/09031936.00138707.

5. Su N, Lin J, Liu G, Chen P, Zhou X, Wan H, et al. an epidemiological survey of current asthma control status in china. Zhonghua Nei Ke Za Zhi. 2014; 53: 601-606. doi: 10.3760/cma.j.issn.05781426.2014.08.006.

6. Malo JL, Provencher S. Occupational asthma. Journal of Allergy \& Clinical Immunology. 2001; 108: 317-328. doi: https://www.ncbi.nlm.nih.gov/pmc/articles/PMC1090538/. 
7. Cook DG, Strachan DP, Carey IM. Health effects of passive smoking. Thorax. 1999; 54: 469. doi: 10.1136/thx.54.5.468a.

8. Cai XL. The study of asthma candidate genes IL-4,IL-13,IL-4R and IL1R1 polymorphisms in Guangxi Black-clothes Zhuang children. Master, YouJiang Medical University For Nationalities, Baise, Guangxi, China, 2017.

9. Tian Y, Xiang X, Juan J, Sun K, Song J, Cao Y, et al. Fine particulate air pollution and hospital visits for asthma in beijing, china. Environmental Pollution. 2017; 230: 227. doi: 10.1016/j.envpol.2017.06.029.

10. Veremchuk LV, Yankova VI, Vitkina TI, Nazarenko AV, Golokhvast KS. Urban air pollution,climate and its impact on asthma morbidity. Asian Pacific Journal of Tropical Biomedicine. 2016; 6: 76-79. doi: 10.1016/j.apjtb.2015.10.001.

11. Zhai WH. The relationship between climatic parameters and air pollutants on emergency room visits for asthma. Doctor, Medical school of Chinese PLA, Beijing, China, 2014.

12. Hebbern $C$, Cakmak S . Synoptic weather types and aeroallergens modify the effect of air pollution on hospitalisations for asthma hospitalisations in Canadian cities. Environmental Pollution, 2015, 204:9-16.

13. Vanos J K, Hebbern C, Cakmak S. Risk assessment for cardiovascular and respiratory mortality due to air pollution and synoptic meteorology in 10 Canadian cities. Environmental Pollution, 2014, 185:322-332.

14. Hoa W C , Hartleyb W R, Myersc L, et al. Air pollution, weather, and associated risk factors related to asthma prevalence and attack rate. Environmental Research, 2007, 104(3):402-409.

15. Zhou L, Quanyuan WU, Cai D, Liu S, Zhang L. Typical air pollutants space-time effects on asthma in jinan city. Journal of Environmental Hygiene. 2015; 2015 :211-214. doi: 10. 13421/ j. cnki. hjwsxzz.2015. 03. 006.

16. Zhang Y, Shao Y, Wang SG, Shang KZ, Wang JY, Li X, et al. Relationship between air pollutant and respiratory diseases hospital outpatient visits in Beijing. China Environmental Science. 2014; 34: 2401-2407.

17. Yan T, Yang DR, Lan L, Wang HX, Wang SG. Relationship between air pollutant and respiratory diseases hospitalization in lanzhou. China Environmental Science. 2013; 33: 175-180. doi: 10.3969/j.issn.1000-6923.2013.01.025

18. Cai J, Zhao A, Zhao J, Chen R, Wang W, Ha S, et al. Acute effects of air pollution on asthma hospitalization in shanghai, china. Environmental Pollution. 2014; 191: 139-144. doi: 10.1016/j.envpol.2014.04.028.

19. Marco Aurélio de Valois Correia Junior, Emanuel Sávio Cavalcanti Sarinho, José Angelo Rizzo, et al. Lower prevalence and greater severity of asthma in hot and dry climate. J Pediatr, 2016, 93(2).

20. Li K, Ni H, Yang Z, Wang Y, Ding S, Wen L, et al. Effects of temperature variation between neighbouring days on daily hospital visits for childhood asthma: a time-series analysis. Public Health. 2016; 136: 133-140. doi: https://doi.org/10.1016/j.puhe.2016.04.002. 
21. Lam HC, Li AM, Chan EY, Rd GW. The short-term association between asthma hospitalisations, ambient temperature, other meteorological factors and air pollutants in hong kong: a time-series study. Thorax. 2016; 71: 1097. doi: 10.1136/thoraxjnl-2015-208054.

22. Xu Z, Huang C, Hu W, Turner LR, Su H, Tong S. Extreme temperatures and emergency department admissions for childhood asthma in brisbane, australia. Occupational and Environmental Medicine. 2013; 70: 730-735. doi: 10.1136/oemed-2013-101538.

23. Son JY, Bell ML, Lee JT. The impact of heat, cold, and heat waves on hospital admissions in eight cities in korea. International Journal of Biometeorology. 2014; 58: 1893-1903. doi: 10.1007/s00484014-0791-y.

24. Sousa S I V , Pires J C M , Martins E M , et al. Short-term effects of air pollution on respiratory morbidity at Rio de Janeiro - Part II: Health assessment[J]. Environment International, 2012, 43(none):0-5.

25. Zhang S,Li G, Tian L, Guo Qun, Pan XC. short-term exposure to air pollution and morbidity of COPD and asthma in East Asian area: A systematic review and meta-analysis $₫$ Environmental Research. 2016; 148: 15. doi: http://dx.doi.org/10.1016/j.envres.2016.03.008.

26. Mireku $\mathrm{N}$, Wang $\mathrm{Y}$, Ager $\mathrm{J}$, et al. Changes in weather and the effects on pediatric asthma exacerbations[J]. Annals of Allergy, Asthma \& Immunology, 2009, 103(3):220-224.

27. Follenweider LM, Lambertino A. Epidemiology of asthma in the united states. Nursing Clinics of North America. 2013; 48: 1-10. doi: https://doi.org/10.1016/j.cnur.2012.12.008.

28. Chan EY, Goggins WB, Yue JS, Lee P. Hospital admissions as a function of temperature, other weather phenomena and pollution levels in an urban setting in china. Bulletin of the World Health Organization. 2013; 91: 576-584. doi: http://dx.doi.org/10.2471/BLT.12.113035.

29. Pollock J, Shi L, Gimbel Outdoor environment and pediatric asthma: an update on the evidence from north america. Canadian Respiratory Journal of the Canadian Thoracic Society. 2017; 3: 8921917. doi: https://doi.org/10.1155/2017/8921917.

30. Ching-Yen K, Ren-Hao P , Chin-Kan C , et al. Application of a Time-Stratified Case-Crossover Design to Explore the Effects of Air Pollution and Season on Childhood Asthma Hospitalization in Cities of Differing Urban Patterns: Big Data Analytics of Government Open Data[J]. International Journal of Environmental Research and Public Health, 2018, 15(4):647-.

31. Chang TS, Gangnon RE, Page CD, Buckingham WR, Tandias A, Cowan KJ, et al. Sparse modeling of spatial environmental variables associated with asthma. Journal of Biomedical Informatics. 2015; 53: 320-329. doi:10.1016/j.jbi.2014.12.005.

32. Zhang $Y, N i H$, Bai $L$, et al. The short-term association between air pollution and childhood asthma hospital admissions in urban areas of Hefei City in China: A time-series study[J]. Environmental Research, 2019, 169:510-516.

33. Sha, L., Shao, M., Liu, C., Chen, Y. The prevalence of asthma in children: a comparison between the year of 2010 and 2000 in urban China. Zhonghua Jie He He Hu Xi Za Zhi 38 (9). 2015, 664-668. 
34. Hua MA, Wang Y, Wang L, Wang Y. Vegetation cover and climate change and rural economic development in relations during last 20 years in karst region of guangxi, china. Mountain Research. 2014; 32: 38-45. doi: 10.16089/j.cnki.1008-2786.2014.01.008.

35. Zhang XB, Wang L H, Guo LP, Wei X, Huang LQ, Liang LK, et al. Analysis of the effect of topographical conditions on the artemisinin content in sweet wormwood herb in guangxi,china. Acta Ecologica Sinica. 2009; 29: 688-697. doi: 10.3321/j.issn:1000-0933.2009.02.017.

36. Guangxi Statistical Bureau. http://tjj.gxzf.gov.cn/tjsj/tjnj/2016/indexch.htm. 2016.

37. The sixth national population census. [http://www.stats.gov.cn/tjsj/]

38. Hastie T, Tibshirani R. Generalized Additive Models. Chapman and Hall. 1990; 1: 587-602.

39. Zhang ZY. Spatiotemporal Distributions of PM2.5 Using Ground Monitor Data and its Relationship with Hospital Visiting of Respiratory Diseases. Doctor, Zhejiang University, Hangzhou, Zhejiang, China, 2016.

40. Kim L. GAM: The Predictive Modeling Silver Bullet. 2015. https://multithreaded.stitchfix.com/blog/2015/07/30/gam/.

41. Dong J, Mengru LI, Sun R, Shen H, Tiemei YI. Study on the air quality standards of china and comparative with foreign standards. Environment and Sustainable Development. 2015; 40: 87-92. doi: 10.3969/j.issn.1673-288X.2015.05.026.

42. Fan J , Li S , Fan C, et al. The impact of PM2.5 on asthma emergency department visits: a systematic review and meta-analysis[J]. Environmental Science and Pollution Research, 2015.

43. Ghorani-Azam A, Riahi-Zanjani B , Balali-Mood M . Effects of air pollution on human health and practical measures for prevention in Iran[J]. Journal of research in medical sciences, 2016, 21(5).

44. Zeng L. The allergic asthma mechanism of Der $f 31$,which is a new allergen of Dermatophagoides farina. Master, Shenzhen university, Shenzhen, China, 2017.

45. Fu YN, Wang J, Xiang L. Distributions and clinical significance of house dust mite allergens in household dust from house dust mite-allergic asthmatic children. Biomedical Engineering and Clinical Medicine. 2012; 16: 586-591. doi: 10.13339/j.cnki.sglc.2012.06.020.

46. Asher MI, Stewart AW, Mallol J, Montefort S, Lai CK, Aït-Khaled N, et al. Which population level environmental factors are associated with asthma, rhinoconjunctivitis and eczema? review of the ecological analyses of isaac phase one. Respiratory Research. 2010; 11: 1-10. doi: 10.1186/14659921-11-8.

47. Alcock I, White M, Cherrie M, Wheeler B, Taylor J, Mcinnes R, et al. Land cover and air pollution are associated with asthma hospitalisations: a cross-sectional study. Environment International. 2017; 109: 29. doi: 10.1016/j.envint.2017.08.009.

48. Ko FW, Tam W, Wong TW, Chan DP, Tung AH, Lai CK, et al. Temporal relationship between air pollutants and hospital admissions for chronic obstructive pulmonary disease in hong kong. Thorax. 2007; 62: 780-785. doi: 10.1136/thx.2006.076166. 
49. Seo, S., Kim, D., Min, S., Paul, C., Yoo, Y., \& Choung, J. T. GIS-based association between PM10 and allergic diseases in Seoul: implications for health and environmental policy," Allergy, Asthma and Immunology Research, 2016, 8(1):32-40.

50. Kim, D., Seo, S., Min, S., Simoni, Z., Kim, S., \& Kim, M. A Closer Look at the Bivariate Association between Ambient Air Pollution and Allergic Diseases: The Role of Spatial Analysis. International Journal of Environmental Research and Public Health. 2018, 15(8), 1625. doi:10.3390/ijerph15081625

51. Martínez-Rivera C, Garcia-Olivé I, Stojanovic Z, Radua J, Ruiz Manzano J, Abad-Capa J. Asociación entre la contaminación ambiental y las agudizaciones de asma bronquial en Badalona (Barcelona), 2008-2016. Med Clin (Barc). 2019;152:333-338.

52. Xu Z, Crooks J L, Davies J M , et al. The association between ambient temperature and childhood asthma: a systematic review. International Journal of Biometeorology, 2017.

\section{Tables}

Table 1. Statistics for asthma hospitalizations and environmental factors in Guangxi in 2015

\begin{tabular}{|c|c|c|c|c|c|c|c|c|c|c|}
\hline Time Categories & Variables & DN & $\begin{array}{c}\mathrm{T} \\
\left({ }^{\circ} \mathrm{C}\right)\end{array}$ & $\begin{array}{l}\text { TDIFF } \\
\left({ }^{\circ} \mathrm{C}\right)\end{array}$ & $\begin{array}{l}\text { RHU } \\
\text { (\%) }\end{array}$ & $\begin{array}{l}\text { WIN } \\
\left(\mathrm{m} \cdot \mathrm{s}^{-1}\right)\end{array}$ & $\begin{array}{c}\mathrm{PM}_{2.5} \\
\left(\mu \mathrm{g} \cdot \mathrm{m}^{-3}\right)\end{array}$ & $\begin{array}{c}\mathrm{SO}_{2} \\
\left(\mu \mathrm{g} \cdot \mathrm{m}^{-3}\right)\end{array}$ & $\begin{array}{c}\mathrm{CO} \\
\left(\mathrm{mg} \cdot \mathrm{m}^{-3}\right)\end{array}$ & $\begin{array}{c}\mathrm{NO}_{2} \\
\left(\mu \mathrm{g} \cdot \mathrm{m}^{-3}\right)\end{array}$ \\
\hline \multirow[t]{4}{*}{ Whole year } & P25 & 17 & 17.8 & 5.7 & 74.1 & 14.2 & 23.6 & 13.4 & 0.9 & 15.1 \\
\hline & P50 & 22 & 25.5 & 7.4 & 81 & 16.9 & 33 & 15.9 & 1 & 17.8 \\
\hline & P75 & 27 & 28.5 & 8.8 & 85.9 & 19.8 & 50.2 & 20.1 & 1.2 & 22.7 \\
\hline & mean & 22.2 & 23.2 & 7.4 & 79.9 & 17.5 & 40 & 17.3 & 1.1 & 20.1 \\
\hline \multirow[t]{4}{*}{ Spring } & P25 & 20 & 21.3 & 5.8 & 74.6 & 15.7 & 28 & 13 & 1 & 15.4 \\
\hline & P50 & 25 & 25.8 & 7.5 & 80.5 & 18.4 & 34.5 & 15.1 & 1 & 17.4 \\
\hline & P75 & 29.3 & 27.8 & 8.7 & 85.3 & 20.7 & 48.5 & 18.1 & 1.1 & 20.3 \\
\hline & mean & 25.5 & 24 & 7.4 & 79.3 & 18.7 & 38 & 15.6 & 1 & 18.3 \\
\hline \multirow[t]{4}{*}{ Summer } & P25 & 14.5 & 27.9 & 6.3 & 75.1 & 15.4 & 18.7 & 12.6 & 0.8 & 13 \\
\hline & P50 & 19 & 29.9 & 7.5 & 80.7 & 17.2 & 22.7 & 14.4 & 0.9 & 14.4 \\
\hline & P75 & 23 & 30.8 & 8.6 & 85.6 & 19.8 & 36.1 & 16.8 & 0.9 & 15.8 \\
\hline & mean & 19.5 & 29.5 & 7.6 & 80.2 & 17.8 & 27.2 & 15 & 0.9 & 14.6 \\
\hline \multirow[t]{4}{*}{ Autumn } & P25 & 18 & 22.9 & 6.2 & 75.4 & 13.6 & 23.6 & 15.6 & 1 & 16.4 \\
\hline & P50 & 22 & 25 & 7.7 & 82.8 & 15.5 & 32.8 & 19.2 & 1.1 & 19 \\
\hline & P75 & 27 & 27.3 & 8.7 & 87.6 & 17.9 & 46.6 & 22.3 & 1.2 & 25.1 \\
\hline & mean & 22.4 & 24.5 & 7.7 & 81.6 & 16 & 36.3 & 19.6 & 1.1 & 21.2 \\
\hline \multirow[t]{4}{*}{ Winter } & P25 & 17 & 12.2 & 4.2 & 71.3 & 13.8 & 32.2 & 13.8 & 1.1 & 19.5 \\
\hline & P50 & 21 & 14.2 & 5.9 & 80.3 & 16.7 & 51.7 & 16.9 & 1.3 & 23.3 \\
\hline & P75 & 25 & 17.8 & 9.2 & 85 & 20.1 & 86.5 & 25.3 & 1.5 & 35.3 \\
\hline & mean & 21 & 14.9 & 6.7 & 78.6 & 17.3 & 59.4 & 19.3 & 1.3 & 26.6 \\
\hline
\end{tabular}

${ }^{1}$ Variables refer to the daily average in 2015. DN means daily number of asthma admissions per 100,000 population; P25, P50 and P75 are the 25th, 50th and 75th percentiles.

Table 2. Synergistic effect of air pollutants and meteorological factors on asthma hospitalizations in 14 regions in Guangxi (2015) 


\begin{tabular}{cccccc}
\hline Regions & R-sq.(adj) & Deviance explained & Regions & R-sq.(adj) & Deviance explained \\
\hline Baise & 0.131 & $29.5 \%$ & Hezhou & 0.029 & $20.4 \%$ \\
Beihai & 0.292 & $40.5 \%$ & Laibin & 0.190 & $26.1 \%$ \\
Nanning & 0.207 & $34.3 \%$ & Liuzhou & 0.184 & $31.8 \%$ \\
\hline Fangchenggang & 0.062 & $21.2 \%$ & Chongzuo & 0.026 & $17.7 \%$ \\
\hline Guigang & 0.095 & $23.4 \%$ & Qinzhou & 0.163 & $26.2 \%$ \\
\hline Guilin & 0.120 & $27.0 \%$ & Wuzhou & 0.159 & $25.6 \%$ \\
Hechi & 0.075 & $21.1 \%$ & Yulin & 0.119 & $26.0 \%$ \\
\hline
\end{tabular}

Note: all results are significant at $p<0.01$

Table 3. Synergistic effect of air quality and meteorological factors on asthma hospitalizations for different age groups in 2015

\begin{tabular}{ccc}
\hline Age groups & R-sq.(adj) & Deviance explained \\
\cline { 1 - 1 } $0-14$ & 0.328 & $37.2 \%$ \\
$15-29$ & 0.122 & $16.9 \%$ \\
$30-44$ & 0.148 & $22.4 \%$ \\
$45-59$ & 0.136 & $23.2 \%$ \\
$60-74$ & 0.189 & $25.9 \%$ \\
$>=75$ & 0.155 & $21.5 \%$ \\
\hline
\end{tabular}

Note: all results are significant at $p<0.01$

\section{Figures}




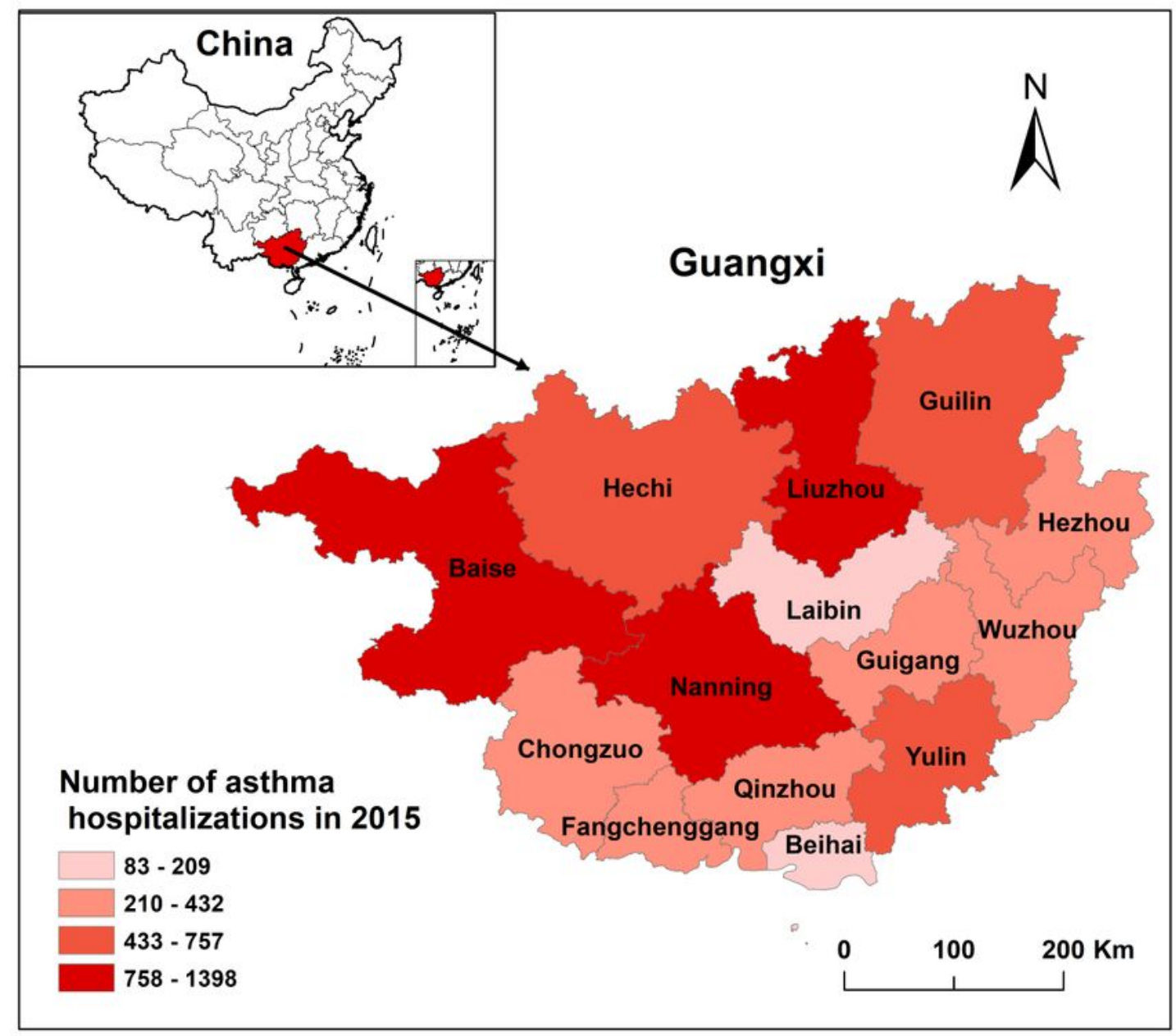

\section{Figure 1}

Geographic location of Guangxi in China, and the number of asthma hospitalization in Guangxi (2015) Description of data: The author drew this map by ArcGIS 10.3 software. Figure 1 showed the geographic location of Guangxi in China and the number of asthma hospital admissions for each region of Guangxi in 2015. Note: The designations employed and the presentation of the material on this map do not imply the expression of any opinion whatsoever on the part of Research Square concerning the legal status of 
any country, territory, city or area or of its authorities, or concerning the delimitation of its frontiers or boundaries. This map has been provided by the authors.

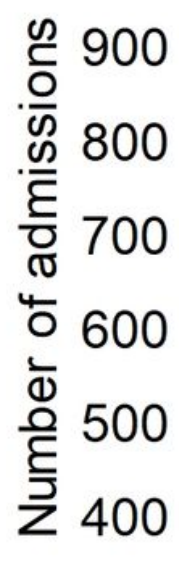

Jan Feb Mar Apr May Jun Jul Aug Sep Oct Nov Dec Month

(a)
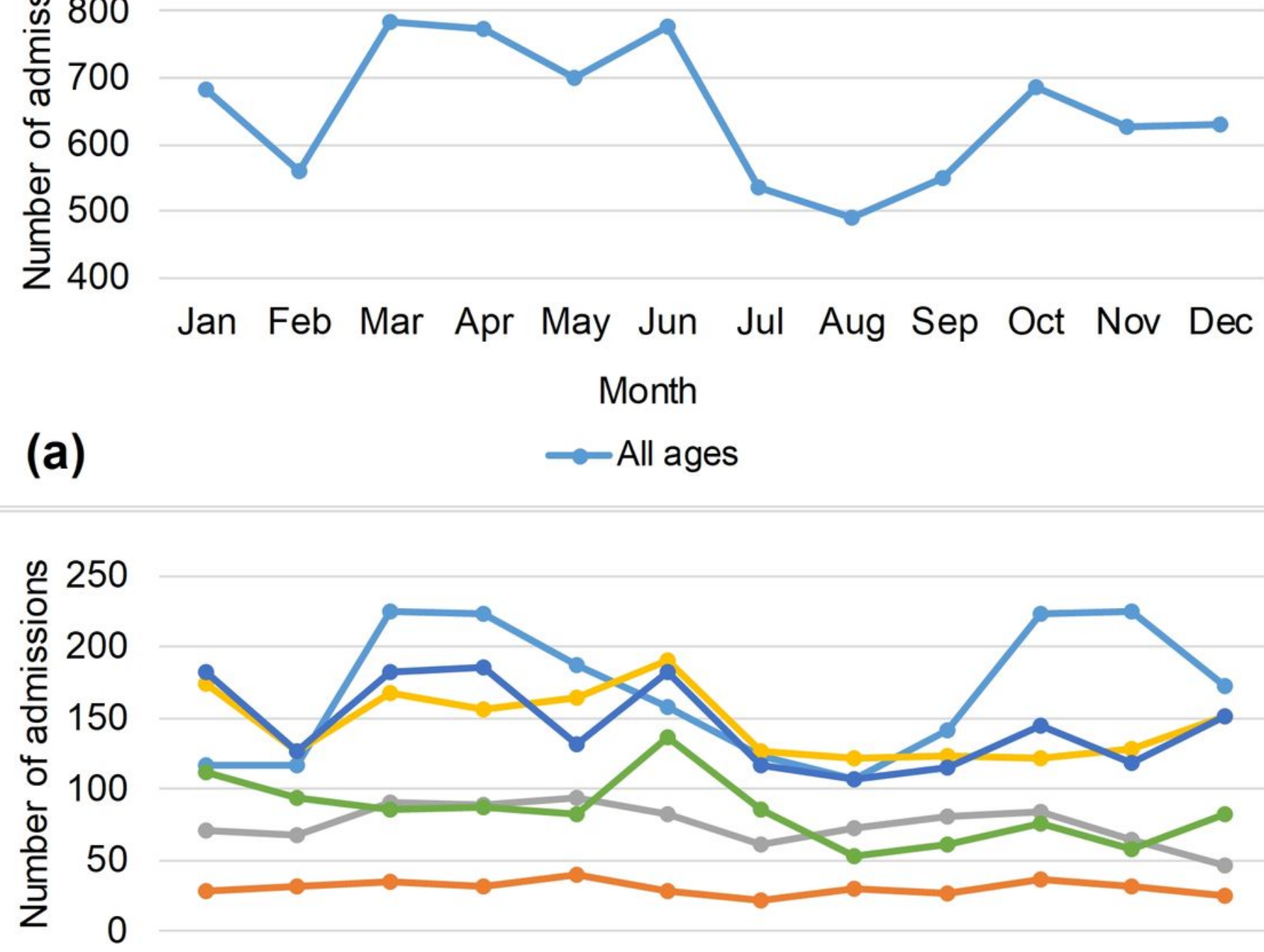

$\longrightarrow$ All ages

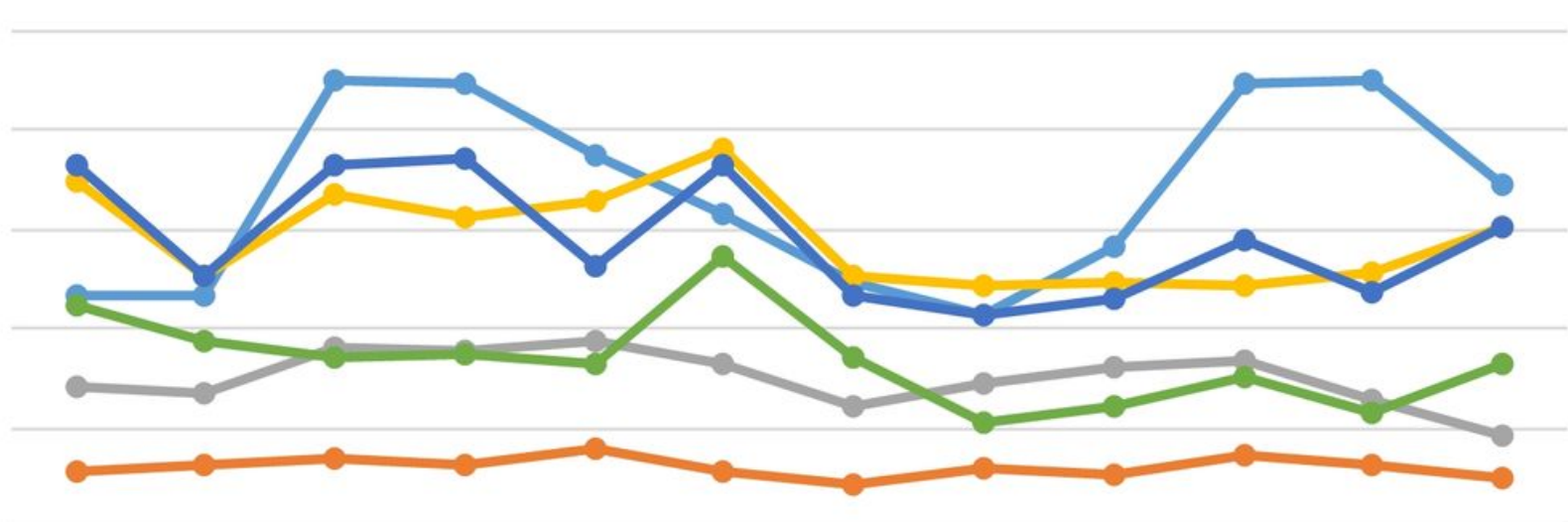

Jan Feb Mar Apr May Jun Jul Aug Sep Oct Nov Dec Month
(b)
$\rightarrow 0-14$
$\rightarrow 15-29$
$\rightarrow 30-44$
$44-59$
$\multimap 60-74 \multimap>75$

Figure 2

(a) Time distribution of asthma hospital admissions in 2015; (b) Time distribution of asthma hospital admissions by age groups in 2015 Description of data: The author drew this map by ArcGIS 10.3 software. In Figure 2a, the total number of asthma hospital admissions for each month was shown in 2015. In Figure $2 b$, the asthma hospitalization numbers of different age groups for each month were shown in 2015 

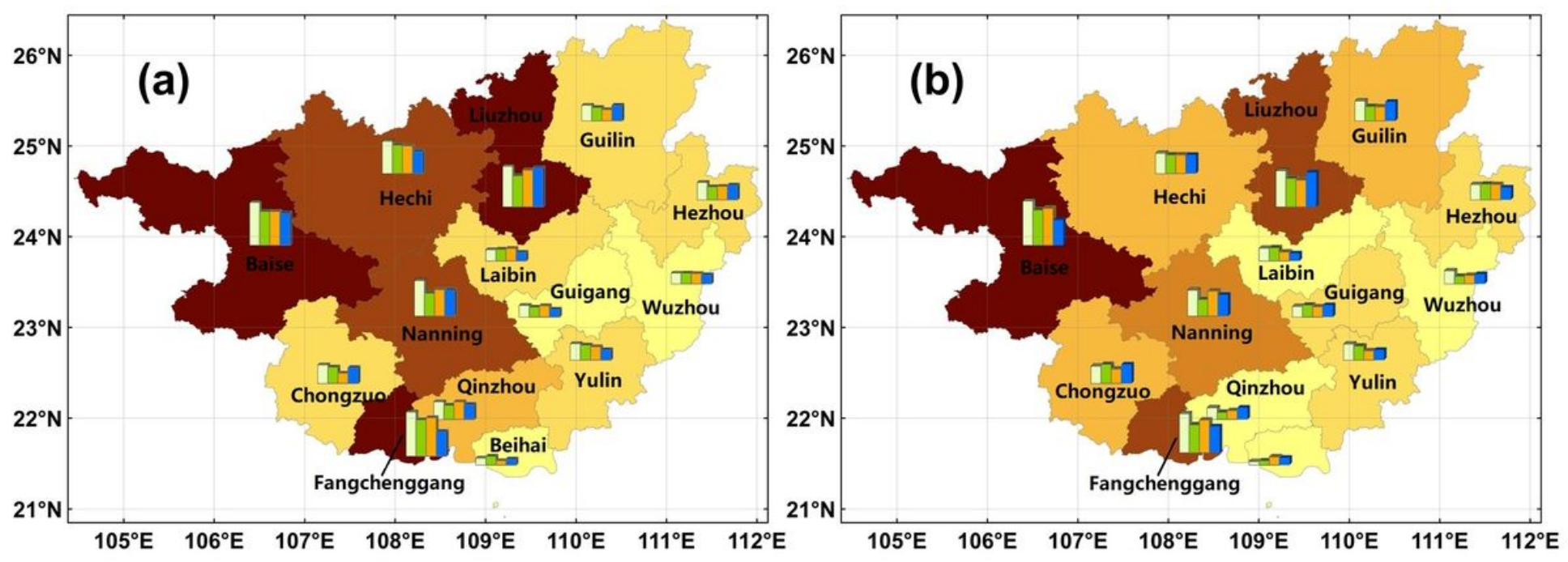

Daily average admission rate per 100,000 population in 2014 and 2015

Admission rate by season

$30-35$

$\square$ Spring $\square$ Summer $\square$ Autumn $\square$ Winter ${ }^{-1}$

\section{Figure 3}

Daily average asthma admission rates for the whole year and seasons in Guangxi in 2014 (a) and 2015 (b). Description of data: The author drew this map by Microsoft Office(2016) for Excel. This study analyzed the spatial distribution of the daily average hospitalization rate (per 100,000 population) of asthma for 14 regions in Guangxi. Figure 3 showed the daily average asthma admission rates for the whole year and seasons in Guangxi in 2014and 2015. Note: The designations employed and the presentation of the material on this map do not imply the expression of any opinion whatsoever on the part of Research Square concerning the legal status of any country, territory, city or area or of its authorities, or concerning the delimitation of its frontiers or boundaries. This map has been provided by the authors. 


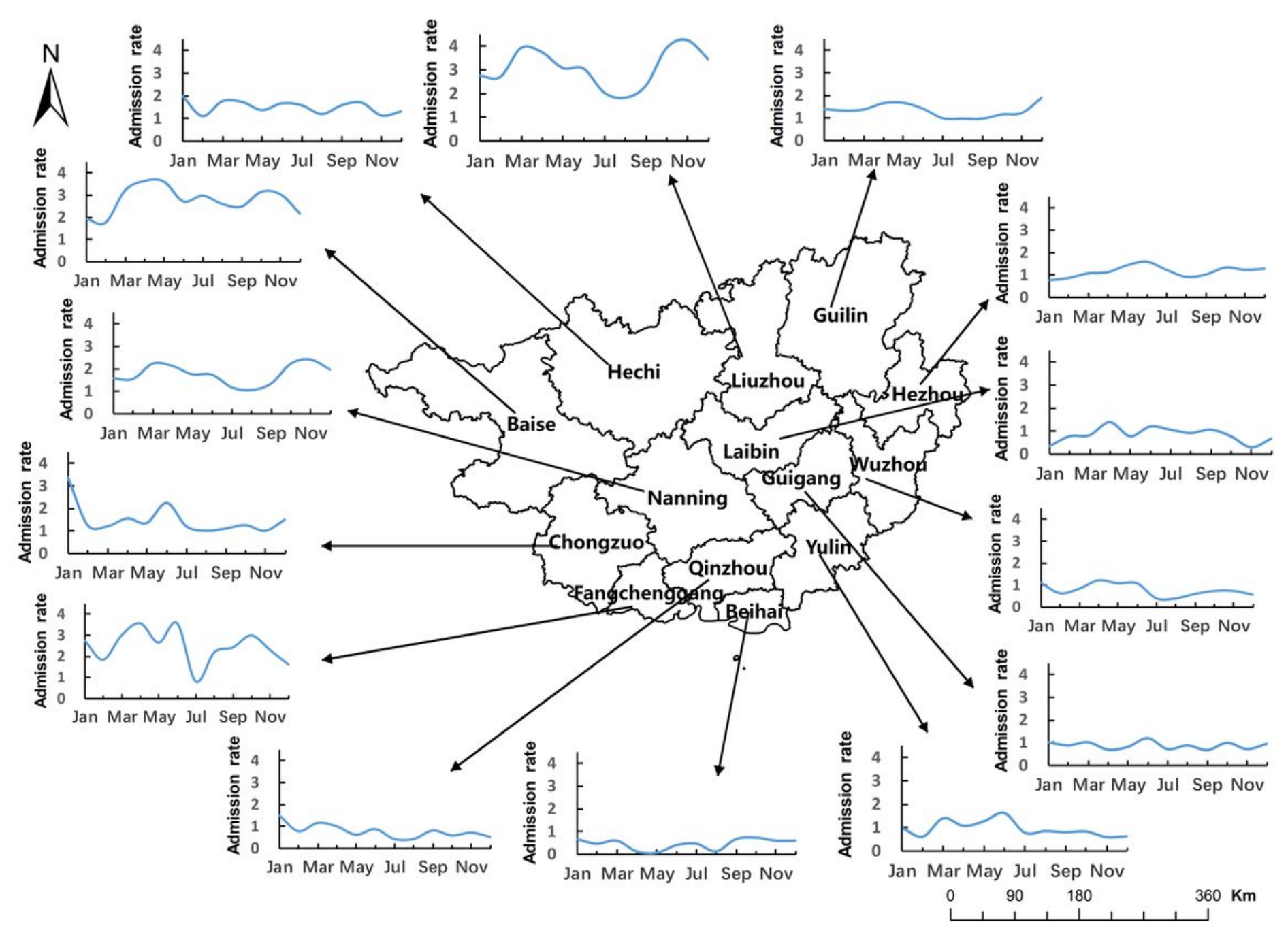

Figure 4

Variations of the average hospitalization rates for asthma in 14 regions in Guangxi (2015) Description of data: The author drew this map by ArcGIS 10.3 software, Microsoft Office (2016) for Excel and Microsoft Visio (2016). When adjusted for regions, the time trends of asthma hospitalization rates for different regions in 2015 were present in Figure 4. Note: The designations employed and the presentation of the material on this map do not imply the expression of any opinion whatsoever on the part of Research Square concerning the legal status of any country, territory, city or area or of its authorities, or concerning the delimitation of its frontiers or boundaries. This map has been provided by the authors. 

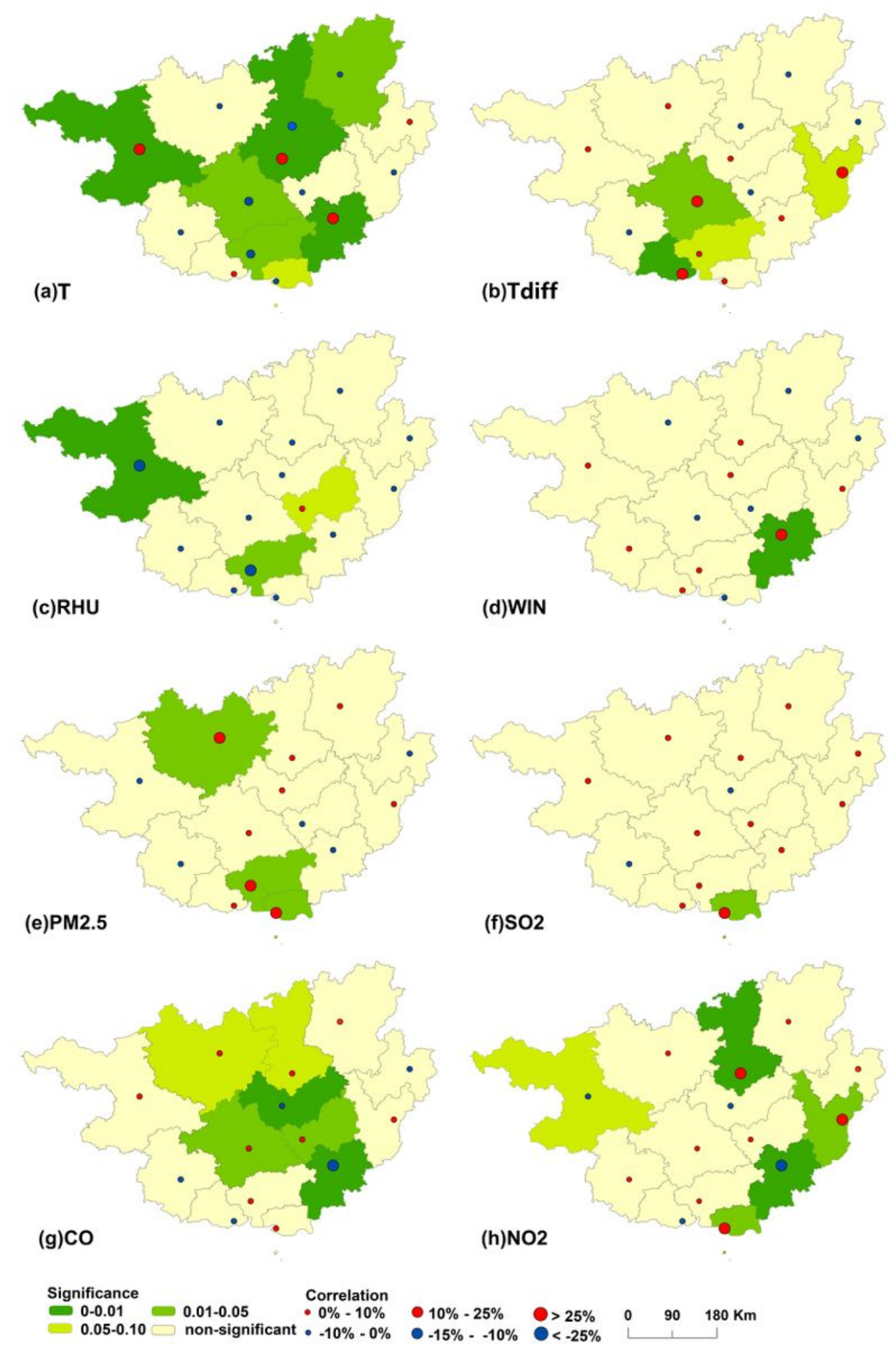

\section{Figure 5}

Single factor analysis for correlation between environmental factors and asthma hospitalization rates in Guangxi (2015) Note: The designations employed and the presentation of the material on this map do not imply the expression of any opinion whatsoever on the part of Research Square concerning the legal status of any country, territory, city or area or of its authorities, or concerning the delimitation of its frontiers or boundaries. This map has been provided by the authors. Description of data: The author drew 
this map by ArcGIS 10.3 software for Excel and Microsoft Visio (2016). According to the result of Spearman, the correlation between air pollutants, meteorological factors and hospital admission rates for asthma in 14 regions in Guangxi was shown in Figure 5. The background color of the map represented the significance for each region, and the dot represented the correlation for each region.

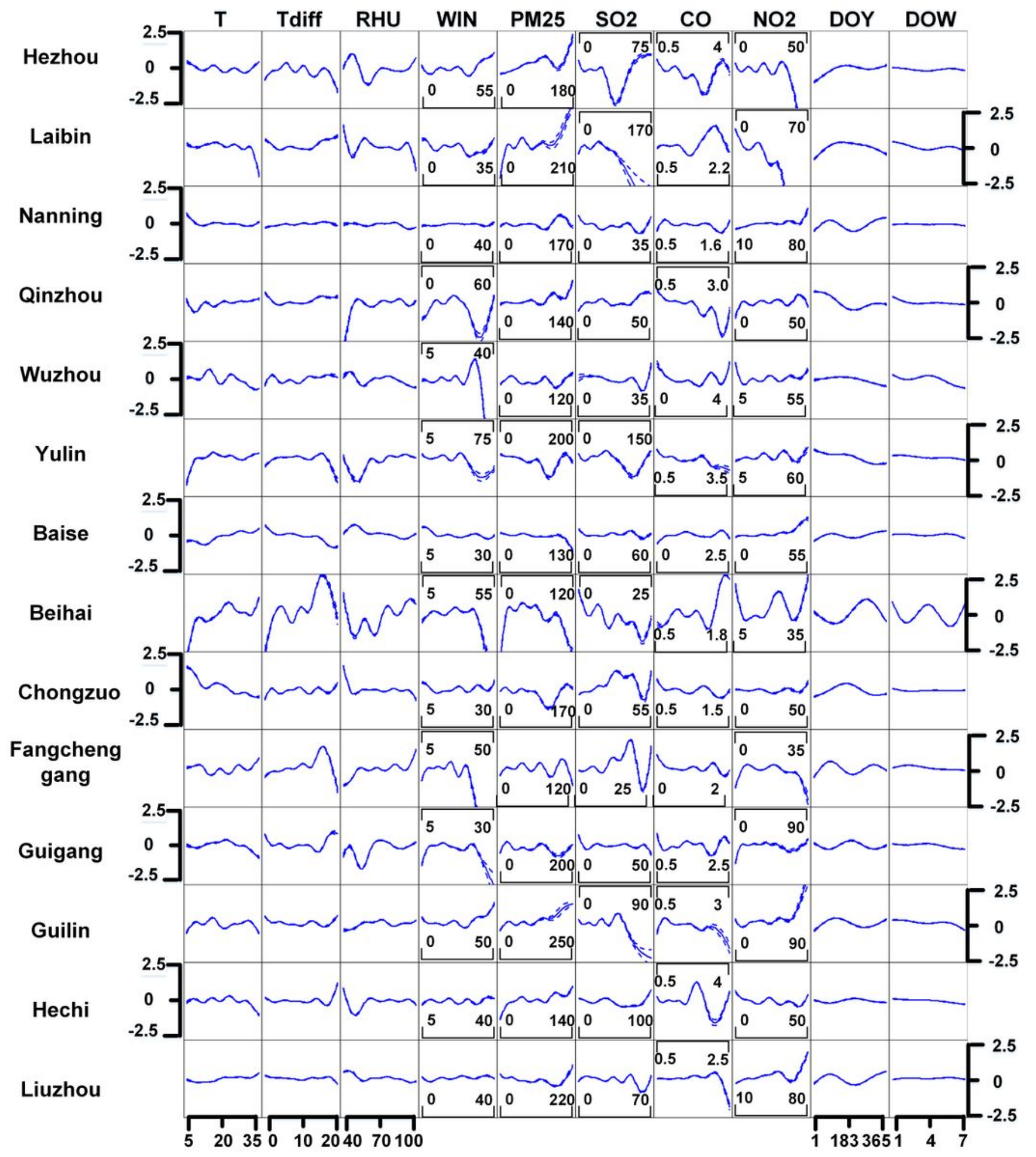

Figure 6 
GAM for the relationship between asthma hospitalization, air pollutants and meteorological factors in 14 regions (2015) Description of data: The author drew this map by ArcGIS 10.3 software for Excel and Microsoft Visio (2016). The fitting effects between meteorological factors, air pollutant concentration and asthma hospitalization rate were shown in Figure 6. 